\title{
Urdimento
}

\section{A TEATRALIDADE EM CLARICE LISPECTOR}

\author{
Alex Beigui
}

\section{Resumo}

$\mathrm{O}$ artigo busca apontar e refletir sobre os aspectos da teatralidade presentes em Clarice Lispector, apontando os índices de materialidade e performatividade da linguagem plástico-sensorial de sua escrita. Para tanto, sustentamos nosso ponto de vista, sobretudo, na tensão entre literariedade e teatralidade que percorrem grande parte de sua produção desde sua obra inaugural Perto do Coração Selvagem.

Palavras-chave: teatralidade, literariedade, Clarice Lispector.

\begin{abstract}
This article comments on some aspects of Clarice Lispector's theatricality. It aims to highlight particular aspects of Lispector's plastic and sensorial text pointing out and discussing about its materiality and performartic qualities. So, this article will look at the existing tension between literality and theatricality which is a constant within Lispector's work since her inaugural work Perto do Coração Selvagem.
\end{abstract}

Keywords: theatricality, literality, Clarice Lispector.

\section{O teatro em crise}

"Vou continuar, é exatamente de minha natureza nunca me sentir ridícula, eu me aventuro sempre, entro em todos os palcos".

“... um instante antes da cena e um instante depois".

(LISPECTOR, 1999: 122-192)

A matéria fugidia com que nos deparamos ao ler os romances e os contos de Clarice Lispector pode parecer, enquanto princípio e num primeiro momento, contraditória ao objetivo deste trabalho: buscar as marcas da teatralidade, lidas aqui como materialidade com que se tecem a construção literária e o universo ficcional em questão. Paradoxo sustentado, sobretudo, pelo campo árido e pouco demarcado de sua escrita e pelo próprio movimento de incompletude dos enredos, além de um conjunto

${ }^{1}$ Alex Beigui, mestre em Artes Cênicas pela UFBA e doutor em dramaturgia brasileira pela USP, atualmente é professor adjunto da UFRN e membro do GT Territórios e Fronteiras da ABRACE. 


\section{Urdimento}

${ }^{2}$ Todas as citações da obra Perto do Coração Servagem foram retiradas da edição cuja referência completa encontra-se presente na bibliografia. de intertextos, citações e imagens que ampliam e enfatizam, por meio de arqueologismos e anacronismos, o fértil campo da subjetividade tão explorado pela crítica especializada e pelas inúmeras montagens cênicas das obras da autora. No entanto, ainda que sua obra recuse a síntese e evoque a pluralidade de modo excessivo, desde o seu primeiro romance, Perto do Coração Selvagem de 1944, tal teatralidade já aparece enquanto questão subjacente ao tema. Com ele, a "crise da representação" inaugura uma diferente forma de preocupação com o ato da escrita, o recurso do fingimento abre paulatinamente espaço para a representação do real intercalada à experiência ou, em alguns casos, à construção de um estilo dramático. Assume-se a própria experiência como condutora da realidade aparente do mundo e das coisas.

Para Alain Touraine (1994: 263): "As crises de mutação que fazem passar da sociedade industrial à sociedade programada correm o risco de fazer desaparecer a consciência de historicidade, e assim a própria idéia de modernidade, mas é também através dessas crises que a idéia de sujeito se desprende do historicismo”. No Brasil, a obra de Clarice é responsável por essa mutação na estética narrativa e, conseqüente, estreitamento das fronteiras entre os planos da história e o plano do discurso. Poderíamos dizer que o problema da mimese marca uma primeira discussão no campo parateatral da escrita clariciana. Vejamos como a questão nos é oferecida à maneira platônica e aristotélica do modo de criação e legitimidade do artista/ criador - aludimos à relação do artista com a sua obra e ao efeito da mimese enquanto conceito de valoração de sua produção na discussão iniciada por Platão e especificamente desenvolvida mais tarde por Aristóteles na Poética.

O primeiro capítulo intitulado "O Pai" traz em primeira instância a preocupação com a origem da experiência e seu modo de apreensão pela lente do escritor (Artista), sem, contudo, privar pela regra de afastamento que dispõe de modo confortável sujeito e objeto, criador e criatura, escritor/ personagem: "A máquina do Papai batia tac-tac... tac-tac-tac". (1980: $11)^{2}$. O problema da identidade a ser construída assume o movimento de desconstrução, do não-lugar do sujeito dentro da referência, tanto no plano da enunciação quanto no plano do enunciado.

Como nos lembra Genette (1972: 72-108): "No interior do universo espácio-temporal dos eventos narrados, o discurso das personagens funciona, por seu turno, como um simulacro do ato de enunciação, no interior do próprio discurso narrativo". Essa interferência do narrador traz as marcas de sua escolha, reveladas sempre por meio de estratégias dramatúrgicas cada vez mais híbridas, colocando o problema da criação de forma dialética: modelo e ruptura, referência e inferência, criação e imitação, ficção e representação.

A Teatralidade em Clarice Lispector. Alex Beigui.

Dezembro 2008 - № 11 
A teatralidade desse modo constitui um ponto de articulação entre o locutor e o locatário, este último estendendo-se às personagens por meio de deslocamentos: "sempre arranjava um jeito de se colocar no papel principal exatamente quando os acontecimentos iluminavam uma ou outra figura" (1980: 13). A ambivalência do discurso acompanha a trajetória testemunhal de Joana que busca, sempre através da palavra-ação, concretizar sua experiência, materializar sua vivência, tornar palpável seu lugar no mundo. Tentativa sempre barrada pela dificuldade de uma identidade fixa, estável: "Nunca é homem ou mulher? Porque nunca não é filho nem filha?” (1980: 15). A busca de si é para Joana a busca do sujeito híbrido.

Seu reconhecimento como sujeito passa por inúmeras tentativas de despersonificação: "sim ela sentia dentro de si um animal perfeito. Repugnavalhe deixar um dia esse animal solto. Por medo talvez da falta de estética" (1980: 17). O estágio primitivo da escritura lida a todo o momento com algo que a ultrapasse exige por parte do leitor atenção sobre a releitura interna da obra, realizada paralelamente à consolidação da persona de Joana, sempre incompleta e teatralizável. $\mathrm{O}$ ato de fingir como forma de atuar no mundo torna-se para Joana a única possibilidade de encontro consigo mesma. Ao contrário de Hamlet que persegue a verdade até suas últimas conseqüências, Joana abre mão da prerrogativa de um "Eu": "Quem sou? Bem isso já é demais" (1980: 20). Talvez pela dura condição imposta pelo narrador: "Mente-se e cai-se na verdade" (1980: 20). Outro ponto que dificulta, pelos sucessivos atos de representação de Joana, o seu reconhecimento enquanto sujeito, são as perguntas impostas de modo beckettiano à professora de Joana: "O que é que se consegue quando se fica feliz?”; “Queria saber: depois que se é feliz o que acontece? O que vem depois?” (1980: 30); “o que deve fazer alguém que não sabe o que fazer de si?” (1980: 73). Essas perguntas funcionam como recurso de trazer o olhar do leitor para a maquete imperfeita do mundo. Equação que nas personagens de Samuel Beckett gera um movimento de esfacelamento da idéia de identidade, impulsionando os personagens, mas impedindo-os de alcançar o que se quer.

Tais questões, incluindo as de caráter mais intimista - "E havia um meio de ter as coisas sem que as coisas a possuíssem?” - conduzem sempre e inevitavelmente ao intervalo e nunca ao encontro entre as demais personagens do romance. Intervalo que, diferentemente do modelo trágico e renascentista do herói cuja trajetória o conduz ao abismo depois de uma seqüência ascensional ou condição privilegiada, leva a "heroína" de Clarice a partir de antemão do abismo, como se de lá jamais ela tivesse saído. O abismo é sempre um ponto de partida para a dúvida e a dispersão. Ele é criado não em torno da personagem, mas está dentro dela, fazendo parte integrante de sua composição. 


\section{Urdimento}

O movimento sempre indeterminado advém do esforço quase sempre inútil por parte de Joana de apreender o tempo passado, restando-lhe a experiência no ato de sua realização. O tempo teatral, isto é, o tempo da eternidade do agora:

"A imaginação apreendia e possuía o futuro do presente, enquanto o corpo restava no começo do caminho, vivendo em outro ritmo, cego à experiência do espírito... Através dessas percepções - por meio delas Joana fazia existir alguma coisa - ela se comunicava a uma alegria suficiente em si mesma”. (1980: 45)

A posição de Joana, nesse sentido, caminha para o não-lugar do drama: “onde o que amava não era trágico, nem cômico" (1980: 46). A consciência dramática desse "não-lugar" aponta, já em Perto do Coração Selvagem para uma situação intermediária, nem trágica nem cômica da existência. Visão reforçada pela força da teatralidade assumida como recurso narrativo. Talvez por esse motivo seja tão presente a situação dialógica nos romances claricianos, invadindo a narrativa como forma de quadros, cenas e acontecimentos. A indeterminação do estado emocional das personagens abre espaço para o uso de recursos próprios ao teatro como, por exemplo, o da "máscara neutra": "E não estou contente nem triste" (1980: 52). A indeterminação e o meiotermo aparecem como forma de permanecer no discurso, mantendo-o e condicionando-o a uma visão tragicômica do mundo. É pela consciência do estar "entre" o julgamento e o infortúnio, a redenção e a culpa que a dúvida, como corolário da crítica sobre a relação causa/efeito, aparece e se fixa.

O “distanciamento" ou "estranhamento", tão caros a Bertolt Brecht, funcionam através do "espanto", estado em que o gesto se intensifica de acordo com o grau de comprometimento que se tem diante da situação. É o que notamos na parte do diálogo que Joana mantém com o Professor:

“- É um pouco simplista o que estou falando, mas não importa por enquanto. Compreende? Toda ânsia é busca de prazer. Todo remorso, piedade, bondade, é o seu temor. Todo o desespero e as buscas de outros caminhos são a insatisfação. Eis aí um resumo, se você quer. Compreende?

- Sim.

- Quem se recusa o prazer, quem se faz de monge, em qualquer sentido, é porque tem uma capacidade enorme para o prazer, uma capacidade perigosa - daí um temor maior ainda. Só quem guarda as armas a chave é quem receia atirar sobre todos.

- Sim...

- Eu disse: quem se recusa... Porque há os... os planos, os feitos de terra que sem adubo nunca florescerá. 
$-E u$ ?

- Vocêe? Não, por Deus... você é dos que matariam para florescer.

(Ela continuava a ouvi-lo e era como se os seus tios jamais tivessem existido, como se o professor e ela mesma estivessem isolados dentro da tarde, dentro da compreensão).

- Não, realmente não sei que conselhos eu lhe daria, dizia o professor. Diga antes de tudo: o que é bom e o que é mau?

- Não sei..." (1980: 54-55)

Apesar de longo, o diálogo demonstra a inserção dentro do romance de enquadramentos e núcleos dramatúrgicos que, como assinalamos anteriormente, invadem a estrutura narrativa. O cerco dramático construído em torno de Joana revela a formação da personagem como algo inquisidor do ponto de vista da criação. Toda a ambiência do romance conduz Joana a assumir uma identidade de si mesma. O esforço causa-lhe vertigem, revelada ora pelo exercício de consciência ora pela experiência do fracasso diante o desamparo da vida, simultaneamente, humana e inanimada: "Depois de não me ver há muito quase esqueço que sou humana, esqueço meu passado e sou com a mesma libertação de fim e de consciência quanto uma coisa apenas viva" (1980: 72). Essa despersonificação do humano frente à fragilidade de identidade ou ao fracasso do entendimento acerca da experiência finita e incompleta, ao contrário do que se poderia supor, aproxima a obra de Clarice do teatro, pois a trajetória da personagem, mesmo sem movimento definido está elaborada no plano da ação. Aqui, cabe a retomada da acepção da palavra "drama" por Stanislavski:

"A vida é ação. Por isso é que a nossa arte vivaz, que brota da vida, é preponderantemente ativa. Não é sem motivo que nossa palavra 'drama' é derivada da palavra grega, que significa 'eu faço'. Em grego, isso se refere à literatura, à dramaturgia, à poesia e não ao ator ou sua arte. Ainda assim temos muito direito a nos apropriar dela” (1999: 69).

Eis um adendo importantíssimo para a configuração do conceito de ação e de drama em Clarice. Ainda no livro A Criação de um Papel de 1999, o mestre russo pontua com precisão seu conceito de "ação" que, segundo ele, difere de "movimento":

"Na maioria dos teatros, incorretamente, toma-se ação no palco como sendo ação externa. Acredita-se, em geral, que as peças têm muita ação, quando as pessoas chegam e partem constantemente, 


\section{Urdimento}

casam-se, separam-se, matam-se ou salvam-se umas das outras. Em suma, que uma peça é rica em ação quando tem um enredo exterior interessante e habilmente tecido. Mas isso é um erro. Ação cênica não quer dizer andar, mover-se para todos os lados, gesticular em cena. A questão não está no movimento dos braços, das pernas ou do corpo, mas nos movimentos e impulsos interiores" (STANISLAVSKI, 1999: 69).

A proximidade com que a crítica aproximou a obra de Clarice de autores como Virginia Woolf e James Joyce, em alguns pontos plenamente justificada, inibiu uma leitura pela via negativa das obras da autora e, em contrapartida, estimulou a exploração do lado intimista de sua escrita, retirando-a às vezes do seu próprio tempo de realização. Dado evidente, mas que não se esgota no espelho subjetivo e epifânico frente ao qual sua obra quase sempre é refletida. Chamo de "via negativa" a necessidade de materialização da experiência em Clarice, a idéia não apenas de realização, mas de processo inacabado ou, nas próprias palavras da autora, do "movimento que explica a forma" (1980: 74).

As vozes que marcam o tempo mnemônico no romance, e que são responsáveis pela própria memória da personagem principal, dão-se em forma de play-back. Joana, assim como Krapp - protagonista de Krapp's Last Tape de Samuel Beckett (1958) -, "sentia vozes, compreendi-as ou não as compreendia. Provavelmente no fim da vida, a cada timbre ouvido uma onda de lembranças próprias subiria até sua memória, ela diria: quantas vozes eu tive..." (1980: 78). A dualidade entre o mundo interno de Joana e o mundo externo se torna cada vez menos demarcada, mesmo quando há esforço para reconhecê-la: "Na verdade ela sempre fora duas, a que sabia ligeiramente que era e a que era mesmo, profundamente. Apenas até então as duas trabalhavam em conjunto e se confundiam" (1980: 82).

Há aqui todo um esforço de compreensão sempre frustrado no plano exclusivamente metafísico da palavra, ocorrendo sobremaneira com a experiência do plano físico, o que explica a forte presença do corpo e das marcas por ele deixadas na experiência de Joana. Esse apelo concreto aos sentidos já marca um primeiro desvio do plano narrativo em sentido ao dramático. Na observação de César Mota Teixeira (2004: 165-173): "A ênfase na apreensão do 'instante já é outro indício de radicalização do projeto (existencial e estético) inaugurado em Perto do Coração Selvagem: novamente à maneira de Joana, narradora-pintora abre e fecha 'círculos de vida', incapaz de alcançar uma totalidade psicológica ou biográfica”.

$\mathrm{O}$ aspecto plástico da narrativa clariciana pode ser considerado o primeiro indício da teatralidade que aqui formulamos. A fala e a ação são os mecanismos que acoplados ao gesto antecedem à palavra em Joana, 
talvez "porque a percepção do gesto vinha-lhe apenas no momento de sua execução - uma bofetada de suas próprias mãos em seu próprio rosto”. (1980: 87). A experiência com o absurdo é revelada na impotência frente a qualquer organização justificável e plausível da existência pelo hábito puro do discurso. No entanto, a experiência com o absurdo se mostra como forma de libertação anárquica e perversa para com o mundo tanto no que abarca sua estabilidade, enquanto uma referência externa ao sujeito, quanto no que toca a mente auto-sugestionável da personagem: "Às vezes ouvia palavras estranhas e loucas de sua própria boca. Mesmo sem entendêlas, elas deixavam-na mais leve, mais liberta” (1980: 87). Aqui, torna-se importante e sintomático o que diz Beckett no ensaio sobre Proust:

"Assim, a distração é felizmente compatível com a presença ativa de nossos órgãos de articulação. Repetindo: a rememoração, em seu sentido mais alto, não se aplica a esses extratos de nossa ansiedade. Estritamente falando, só podemos lembrar do que foi registrado por nossa extrema desatenção e armazenado naquele último e inacessivel calabouço de nosso ser, para o qual o Hábito não possui a chave”. (BECKETT, 1986: 24)

Disto segue-se o plano contra o campo do conhecido e do perpectivismo que em Clarice se altera pelo desvio. Por outro lado, abre-se o horizonte da irrecuperabilidade do passado, estando o tempo sujeito ao processo de decantação. Outro recurso importante em Perto do Coração Selvagem está concentrado na forma dialética movimento / imobilidade, ponto sob o qual colidem a inquietação da busca e o desamparo do desencontro, este último sempre triunfando sobre o encontro: "A covardia é morna e eu a ela me resigno, depondo todas as armas de herói que vinte e sete anos de pensamento me concederam. O que sou hoje, nesse momento? Uma folha plana, muda, caída sobre a terra. Nenhum movimento de ar balançando-a". (1980: 89)

Antes de pensar o conceito, pensemos o movimento da obra não como dilatação da experiência narrada, mas de afunilamento da mesma; a expansão, presente e ativa no gênero épico cede, gradativamente, lugar à constrição do lugar intermediário da personagem, nem completamente dentro nem completamente fora. Cria-se assim, uma espécie de "foco" que delimita a área de atuação da personagem e, no caso de Clarice, encontra o seu apogeu em A Paixão Segundo G. H. (1964), mais precisamente no quarto de empregada que G. H. resolve visitar. Ainda no caso específico de Joana, o espaço de uma pressuposta liberdade de atuação (os diferentes planos espácio-temporais pelos quais ela se desloca) só acontece com o reconhecimento do aprisionamento na linguagem: "Era uma falsa revolta, uma tentativa de libertação que vinha, sobretudo, com 


\section{Urdimento}

muito medo de vitória" (1980: 95). O fracasso diante da experiência como auto-realização e enquanto drama histórico, em Clarice, corresponde à queda dos valores humanos tão presentes nas manifestações literárias do pós-guerra e ao conseqüente redimensionamento da idéia de sujeito e de sua identidade em crise. Acerca disso, esclarece-nos Júlio Galharte:

"Há uma crescente atmosfera de crise com relação à linguagem que atinge o artista moderno. Tal atmosfera se faz presente nos textos de Lispector e Beckett no aflorar de alguns verbetes-chave em comum, como 'fracasso' ou 'falha da linguagem', por exemplo" (GALHAERTE, 2004: 70).

Ainda no que diz respeito à linguagem beckettiana acrescenta o autor:

"Fracasso e falha. Esses são nomes dados pelos 'eus' dos textos beckettianos para o resultado da busca de uma linguagem que mostre sua alma. Os enunciadores do autor assumem sua inépcia comunicativa e um indicativo desse aspecto é a repetição exaustiva de palavras uma ao lado da outra, como que para mostrar que o enunciado foi acometido de um acesso de gagueira" (GALHAERTE, 2004: 70).

Percorreremos esses "riscos" e "falhas" no corpo do texto clariciano como índices latentes de teatralidade. No entanto, em Clarice assim como em Beckett, os valores apesar de trazerem ressonâncias históricas que culminam com a sua negação, eles não perdem a conotação positiva de denúncia, ainda que sem caráter panfletário. Trata-se antes de uma constatação deliberada da vida em seu estado puro de crueldade, sem nostalgia ou utopias. Em relação aos homens revela a a narradora Clarice através da personagem Joana:

"Se eu os procuro, exijo ou dou-lhes o equivalente das velhas palavras que sempre ouvimos, 'fraternidade', 'justiça'. Se elas tivessem um valor real, seu valor não estaria em ser cume, mas base de triângulo. Seria a condição e não o fato em si. Porém terminam ocupando todo o espaço mental e sentimental exatamente porque são impossíveis de realizar, são contra a natureza" (1980: 100).

Nesse sentido, o conto Mineirinho é uma construção exemplar. Em Clarice, a quebra de utopias e a ausência de uma conotação nostálgica contradizem a própria idéia de busca, mas a amplia e a redimensiona. Pelo menos, a "busca" no sentido de transição, de entrega total para a fisicalização da linguagem. A experiência com a palavra surge, então, sempre de uma organização proposital de torná-la plástica (visível, sonora, auditiva, olfativa, tátil), o que dificulta a leitura estritamente estrutural de sua obra. Para Joana, 
o pouco entendimento que tem de si mesma vem pela indistinção entre corpo e espírito e os seus respectivos lugares na experiência: "E foi tão corpo que foi puro espírito" (1980: 104). A tentativa de tornar presente a experiência insurge no romance sob vários aspectos, incluindo o estatuto filosófico. Só que ao contrário do que a filosofia pode explicar, interessa à narradora exatamente o que escapa à razão e à inteligência, pois:

"É necessário certo grau de cegueira para poder enxergar determinadas coisas. É essa talvez a marca do artista. Qualquer homem pode saber mais do que ele e raciocinar com segurança, segundo a verdade. Mas exatamente aquelas coisas escapam à luz acesa. Na escuridão tornam-se fosforescentes" (1980: 126).

A analogia ao par "luz/escuridão" aparece também sob o argumento filosófico da citação "Espinosa/Dante", respectivamente introduzida em Perto do Coração Selvagem. Sobre isso é relevante o esclarecimento que Marilena Chauí fez da questão em Espinosa:

“... em Espinosa, a luz (a substância) se refere e sempre se reflete nos modos finitos, porque estes são expressões determinadas dela: não só o intelecto finito conhece o mesmo e da mesma maneira que o infinito, do qual é parte, como também conhece a essência e potência do ser absoluto tais como são em si mesmas, e a diferença entre idéia inadequada (parcial, mutilada, abstrata) e adequada (total, genética, concreta) é a diferença entre a luz quando difratada pela imaginação e quando refletida pelo intelecto, pois a primeira é aquela que possuímos quando o absoluto não constitui apenas a essência de nossa mente singular e sim muitas mentes singulares simultâneas (a pluralidade de ondas que se cruzam e se interrompem no ponto de refração), enquanto a segunda é aquela que produzimos quando o absoluto constitui apenas a essência singular de nossa mente (a infinitude de ondas vindas de todos os lados e de todas as direções refletindo-se, sem perda nem desvio, num único ponto singular." (CHAUÍ, 1999: 62)

Esse "ponto singular" em Clarice é sempre o "Sujeito" reconhecido na contínua dualidade Sujeito/Outro. A experiência negativa adotada pelo ponto de vista narrativo corrobora para um melhor entendimento da posição anti-heróica de Joana. Aqui, ao contrário de Édipo, a cegueira deixa de ser um ato-punitivo fruto da inconsciência do herói sobre os fatos e passa a se configurar como aceitação do abismo sendo este fato encarado como "defeito desejado" no curso dos acontecimentos referentes à experiência da protagonista Joana: 


\section{Urdimento}

"Sim, sim, foi isso, não fugir de mim, não fugir de minha letra, como é leve e horrível teia de aranha, não fugir de meus defeitos, meus defeitos, eu vos adoro, minhas qualidades são tão pequenas, iguais às dos outros homens, meus defeitos, meu lado negativo é belo e côncavo como um abismo" (1980: 127)

Esse desnudamento da personagem frente à lente do leitor menos atento pode expressar apenas uma forma de contraposição com o real, mas levado a cabo junto à própria concepção de criação da obra aponta para uma imprecisão formal: a desarticulação da experiência da personagem com o foco narrativo. A voz de Joana se espalha pelo campo narrativo de modo contraproducente ao efeito de unidade. Esta, tal qual na tragédia moderna, dissipa-se e os acontecimentos narrados passam a existir em função de uma soberana consciência dramática: "A tragédia moderna é a procura vã de adaptação do homem ao estado de coisas que ele criou” (1980: 129).

Se a procura é vã, não o é menos o caráter assistencialista das instituições a começar pela célula mater. Esse processo de desconstrução das bases institucionais que legitimam a condição social do sujeito no mundo, já presente em Perto do Coração Selvagem em forma embrionária, encontrará sua forma mais elaborada nos livros-contos da autora, entre eles Laços de Família (1961) e Felicidade Clandestina (1971), sob este aspecto, são os mais significativos. Característica que aponta para uma obra que, apesar da dispersão que assola as personagens, priva pela continuidade temática e pelos seus aspectos de organização. Elos que se ramificam na escritura clariciana e constroem, por meio de camadas, o movimento de adensamento de pontos aparentemente superficiais.

A família acaba em Clarice na própria base que a alicerça: a incomunicabilidade. Nesse sentido a posição de Joana quando indagada por Lídia em situação dialógica, mais do que uma crítica ao casamento, mostra-se como atestado do seu fracasso enquanto instituição:

"Eu pensava: nem a liberdade de ser infeliz se conservava porque se arrasta consigo outra pessoa. Há alguém que sempre a observa, que a perscruta, que acompanha todos os seus movimentos. E mesmo o cansaço da vida ter certa beleza quando é suportado sozinha e desesperada - eu pensava. Mas a dois, comendo diariamente o mesmo pão sem sal, assistindo a própria derrota na derrota do outro... Isso sem contar com o peso dos hábitos refletidos nos hábitos do outro, o peso do leito comum, da mesa comum, da vida comum, preparando e ameaçando a morte comum" (1980: 159) 
Qualquer idéia de "felicidade" em Clarice não pode ser encarada sem o transtorno de sua reverberação. A própria questão da origem das coisas que já aparece, aqui, e sobre a qual aludimos no início deste capítulo, não deve ser compreendida fora da idéia de deformação e de fracasso, e da idéia de inutilidade da criação que se crer validada por um futuro de respostas positivas. Sobre isso, a imagem de Lady Macbeth trazida por Joana no que tange à maternidade parece a mais adequada: "Mas depois, quando eu lhe der leite com estes seios frágeis e bonitos, meu filho crescerá de minha força e me esmagará com sua vida. Ele se distanciará de mim e eu serei a velha mãe inútil. Não me sentirei burlada. Mas vencida apenas e direi: eu nada sei, posso parir um filho e nada sei” (1980: 167). O espaço do "nada sei” é também o espaço do "entre", do "intervalo", não mais o tempo cronológico, apreendido no fluxo de uma consciência ativa e desperta, mas um tempo invadido pela interrupção do fluxo inconsciente no ato mesmo de sua reflexão-execução; no aqui e agora descomprometidos com a ordem das coisas.

"Deixando depois de si o intervalo perfeito como um único som vibrando no ar. Renascer depois, guardar a memória estranha do intervalo sem saber como misturá-lo à vida. Carregar para sempre o pequeno ponto vazio - deslumbrado e virgem, demasiado fugaz para se deixar desvendar" (1980: 168).

É nesse sentido que a citação de James Joyce presente na primeira página, logo após o título do livro, mais que uma referência remetida com o intuito de diálogo entre "estilos", conduz o leitor a enfrentar o desamparo dramatizado na experiência de Joana e na própria solidão do ato criador. Aqui temos mais um ponto de aproximação com o axioma proposto por Beckett e por ele levado a cabo no processo formal de sua obra: "Estamos sós. Incapazes de compreender e incapazes de sermos compreendidos". É no enfrentamento de si que a existência de Joana se dá de modo muito próximo do teatral; o "como se" tão caro a Stanislávski e que aparece inúmeras vezes no interior do romance conduz ao ato de representação: "Como se fosse mentira a sua existência” (1980: 175). Em Clarice a personagem é sempre encarada do ponto de vista da criação, ou melhor, da relação imperfeita entre criador/criatura.

A identidade da personagem oscila em todos os níveis possíveis, afastando-se de qualquer relação de dependência entre os fatos narrados e sua verossimilhança. Desse modo, a dissolução da identidade, impossível de ser apreendida em sua totalidade, aparece até no plano sexual da personagem: "homem assim era Joana, homem. E assim fez-se mulher e envelheceu” (1980: 183). Mais que uma crítica ao universo masculino, como, aliás, a crítica feminina sobre Clarice não cansa de repetir, o que está em jogo não é apenas a questão 


\section{Urdimento}

de gênero, mas, sobretudo, a matriz de uma escrita andrógina referente, sobretudo, ao não-lugar do sujeito: "Eles dois eram duas criaturas. Que mais importa?” (1980: 182). Matriz responsável pela condição insuficiente do sujeito no mundo: "É que tudo o que eu tenho não se pode dar. Nem tomar. Eu mesma posso morrer de sede diante de mim”. (1980: 191). A aceitação da solidão como único caminho possível se caracteriza de modo determinante no espaço fechado, palco italiano, foco ainda que imaginário, no qual as personagens claricianas se vêem. Nesse sentido, Joana é um exemplo primoroso da crise experimentada pelas personagens no drama moderno: "havia um círculo intransponível e impalpável ao redor daquela criatura, isolando-a” (1980: 194.)

A interposição de diálogos abundantes nos textos narrativos de Clarice, juntamente, com o isolamento típico de suas personagens, forma um paradoxo da escrita que beira o estiolamento da narrativa, salvo não fosse o ímpeto analítico da "busca" que a mantém.

A tentativa de aproximação nunca consegue transpor o limite anteposto pela fronteira do ser. Todas as tentativas de ajuste entre esses limites fracassam, restando por vezes apenas a consciência de síntese: "tu és um corpo vivendo, eu sou um corpo vivendo, nada mais” (1980: 201). Daí resulta a imperfeição do movimento assumido como matéria de expressão: “... e eu só sei usar palavras e as palavras são mentirosas...”, ou ainda mais contundente: “... serei brutal e mal feita...” (1980: 216). O ser-personagem é-nos dado em forma de exercício, um laboratório de criação e de novas simetrias em andamento.

\section{Referências bibliográficas}

BECKETT, Samuel. Proust. Trad. Arthur Rosen Blat Nestrovski. São Paulo: L\&PM Editores, 1986.

CHAUİ, Marilena. A Nervura do Real: Imanência e Liberdade em Espinosa. São Paulo: Companhia das Letras, 1999.

GALHARTE, Julio Augusto Xavier. "Na Trilha da Despalavra: Silêncios em Obras de Clarice Lispector e Samuel Beckett”. In: Leitores Leituras de Clarice Lispector. Org. Regina Pontieri. São Paulo: Editora Hedra, 2004.

LISPECTOR, Clarice. Perto do Coração Selvagem. $9^{\mathrm{a}}$ ed. Rio de Janeiro: Nova Fronteira, 1980.

STANISLAVSKI, Constantin. A Criação de um Papel. Trad. Pontes de Paula Lima. $6^{\text {a }}$ ed. Rio de Janeiro: Civilização Brasileira, 1999.

TOURAINE, Alain. Crítica da Modernidade. Trad. Elia Ferreira Edel. Petrópolis-RJ: Vozes, 1994.

TEIXEIRA, César Mota. “O Monólogo Dialógico: Reflexões sobre Água Viva de Clarice Lispector”. In: Leitores e Leituras de Clarice Lispector. (Org. Regina Pontieri). São Paulo: Editora Hedra, 2004. 